\title{
The interplay between direct-acting antivirals and hepatocellular carcinoma in chronic hepatitis C
}

\author{
Sun Hong Yoo, Jung Hyun Kwon \\ Department of Internal Medicine, Catholic University Liver Research Center, The Catholic University of Korea, Seoul 06591, Korea.
}

Correspondence to: Prof. Jung Hyun Kwon, Department of Internal Medicine, Catholic University Liver Research Center, The Catholic University of Korea, Seoul, Korea. E-mail: doctorkwon@catholic.ac.kr

How to cite this article: Yoo SH, Kwon JH. The interplay between direct-acting antivirals and hepatocellular carcinoma in chronic hepatitis C. Hepatoma Res 2020;6:9. http://dx.doi.org/10.20517/2394-5079.2019.49

Received: 15 Dec 2019 First Decision: 3 Feb 2020 Revised: 17 Feb 2020 Accepted: 26 Feb 2020 Published: 6 Mar 2020

Science Editor: Ming-Lung Yu Copy Editor: Jing-Wen Zhang Production Editor: Tian Zhang

\begin{abstract}
Direct-acting antivirals (DAAs) have been introduced for the treatment of hepatitis $C$ virus, and the sustained virological response rate after DAAs was reported to be over $95 \%$. Because of the high sustained virological response rate, the risk of hepatocellular carcinoma (HCC) was expected to be reduced. However, an unexpected high risk of HCC recurrence after DAA treatment was reported, and thus the dispute about the association of DAA and HCC arose. The present article reviews the interplay between DAAs and HCC.
\end{abstract}

Keywords: Chronic hepatitis C, hepatocellular carcinoma, direct-acting antivirals

\section{INTRODUCTION}

Hepatocellular carcinoma (HCC) is the fifth most common cancer in the world and the most common primary liver cancer. The major causes of HCC are cirrhosis of any cause, chronic hepatitis B, chronic hepatitis $\mathrm{C}(\mathrm{CHC})$, alcohol, and nonalcoholic fatty liver disease. Among the causes, the incidence of chronic viral hepatitis-related HCC is 3\%-5\% per year in patients with cirrhosis and $<1.5 \%$ per year in patients with both hepatitis $\mathrm{C}$ and stage 3 fibrosis ${ }^{[1]}$. The sustained virological response (SVR) rate for pegylated interferon (IFN)-based therapy has been reported to be $42 \%-65 \%$ for genotype 1 and $74 \%-93 \%$ for genotype 2 virus $^{[2-4]}$. Despite the low SVR, several previous retrospective studies suggest that achieving SVR after pegylated IFN plus ribavirin therapy reduces the risk of hepatic decompensation, liver related mortality, liver transplantation, and $\mathrm{HCC}^{[5-7]}$.

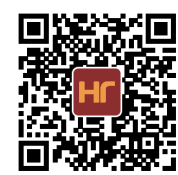


Recently, an IFN-free regimen as a treatment for $\mathrm{CHC}$ including NS3/4A protease inhibitor, NS5A inhibitor, and NS5B polymerase inhibitor was introduced. There have been several reports indicating that the SVR rate is up to $97.8 \%$ and the adverse event rate at all stages of $\mathrm{CHC}$ is lower in patients treated with direct-acting antivirals than IFN-based therapy ${ }^{[8-12]}$. Despite expectations of a decrease in the incidence of HCC because of the high rate of SVR, Reig et al. ${ }^{[13]}$ reported an unexpected high rate of HCC recurrence after treating with direct-acting antivirals (DAA) in patients who experience previous HCC. Conti et al. ${ }^{[14]}$ also reported a high rate of HCC recurrence (28.81\%) 24 weeks after DAAs. Since the two aforementioned reports were published, much debate has been raised about the recurrence and occurrence of HCC after treating DAAs.

In this article, we review the pros and cons of the effects of the DAAs on occurrence/recurrence of HCC.

\section{THE INTERPLAY BETWEEN DIRECT-ACTING ANTIVIRALS AND OCCURRENCE OF HEPATOCELLULAR CARCINOMA}

CHC is the most common cause of HCC worldwide. The incidence of HCC is below $1 \%$ per year in CHC patients without liver cirrhosis ${ }^{[15]}$. However, the risk of HCC increases by $2 \%-8 \%$ in CHC with liver cirrhosis $^{[16]}$.

The papers on HCC occurrence related to DAAs are listed in Table 1. A negative paper was first published on the occurrence of the HCC after the treatment of DAAs. In 2016, Conti et al. ${ }^{[14]}$ published the first report about early occurrence of HCC in hepatitis C virus-related cirrhosis treated with DAAs. They retrospectively analyzed 285 consecutive cirrhotic patients who completed antiviral therapy with DAA regimens and HCC developed in 9 of 285 patients $(3.16 \%, 95 \% \mathrm{CI}: 1.45-5.90)$ during the 24 -week posttreatment evaluation. The report concluded that DAA-induced resolution of HCV infection does not seem to reduce occurrence of HCC.

Since the publication of the previous paper, several papers have been published indicating that DAAs are not associated with occurrence of HCC. A thesis against the previous study was published by Kanwal et al. ${ }^{[17]}$ in 2017. This retrospective cohort study included 22,500 patients who received DAA treatment; $39.0 \%$ of the patients had cirrhosis and $86.74 \%$ achieved SVR. The incidence rate of HCC was 0.90 per 100 person-year (95\%CI: 0.77-1.03) in patients with SVR and 3.45 per 100 person-year (95\%CI: 2.73-4.18) in patients without SVR.

A large prospective study of 2249 patients with HCV-associated cirrhosis was published in Italy by Calvaruso and his colleagues ${ }^{[18]}$. SVR after DAA treatment was achieved in $95.2 \%$ of patients and the overall rate of HCC occurrence was 3.4\%. They analyzed the HCC incidence according to achieved SVR, and HCC occurrence was $3 \%$ in SVR group and $12.8 \%$ in non-SVR group $(P<0.001)$. Although this study did not contain the analysis of control group, they found the SVR to DAA treatment decreased the incidence of HCC. A similar study in the same country including 3917 patients with fibrosis stage $\geq$ F3 was published by Romano and colleagues ${ }^{[19]}$. This large, prospective cohort study showed that the incidence of HCC occurrence was $0.42 \%$ in $\mathrm{F} 3,1.88 \%$ in cirrhosis, and 0.97 per 100 person-year (95\%CI: $0.73-1.26$ ) in all patients.

Nagata et al. ${ }^{[20]}$ compared data between IFN-based and IFN-free regimens for occurrence of HCC. This report included 1085 patients treated with IFN and 669 patients treated with DAAs. The cumulative incidence of HCC occurrence after SVR was 2.6\% (five-year incidence) in IFN-based and 3.3\% (threeyear incidence) in IFN-free therapies. Although the incidence of HCC appears to be higher in IFN-free group than IFN-based group, there are no significant differences between the two groups after performing 


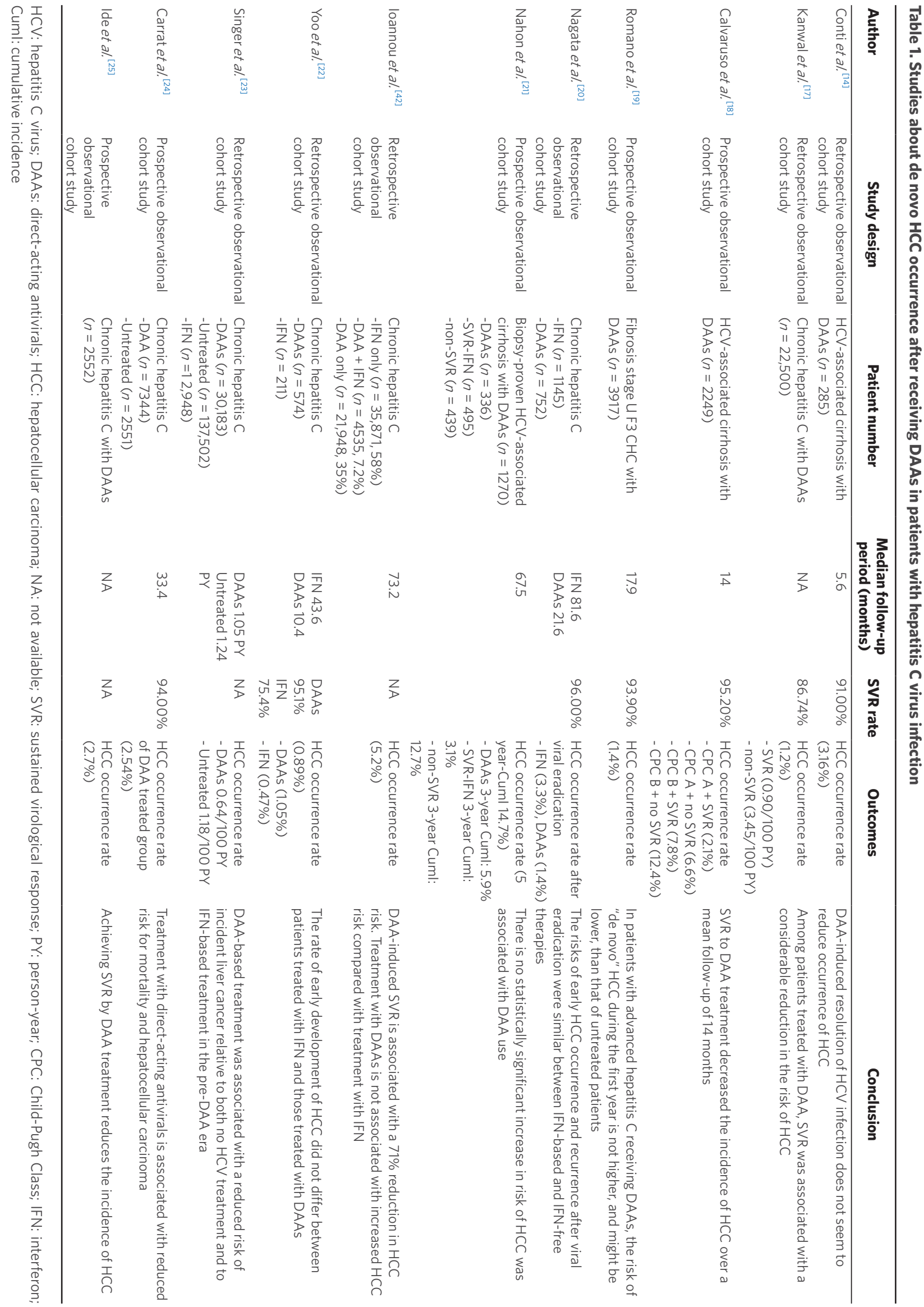


propensity score-matched analysis (three-year incidence: $3.3 \%$ in IFN-based therapy and $1.4 \%$ in IFN-free therapy; $P=0.49$ ). In a study from France, Nahon et al. ${ }^{[21]}$. published a report about the incidence of HCC after DAA for HCV in patients with cirrhosis included in surveillance programs The retrospective cohort study included 1270 patients with biopsy-proven cirrhosis and classified into DAA group $(n=336)$, SVR-IFN group $(n=495)$, and non-SVR group $(n=439)$. The three-year cumulative incidences of HCC were $5.9 \%$ in the DAA group, $3.1 \%$ in the SVR-IFN group, and $12.7 \%$ in the non-SVR group (HR: 2.03, 95\%CI: 1.07-3.84, $P=0.03$ for the DAA group $v s$. the SVR-IFN group). However, under propensity score matched analysis, there was no significant increase in risk of HCC for DAA use (HR: 0.89, 95\%CI: $0.46-1.73, P=0.735$ ). The DAA group was older, and had a higher rate of diabetes or portal hypertension than SVR-IFN group. These features suggested that a more advanced liver disease, older age, and higher rates of comorbidities favor liver carcinogenesis. Yoo et al. ${ }^{[2]}$ published similar comparative data of de novo HCC occurrence in DAA group and IFN group. The cumulative incidence of HCC occurrence was not different between DAA group and IFN group $(P=0.827)$. In USA, Singer et al. ${ }^{[23]}$ analyzed 30,138 patients receiving DAA treatment, 137,502 patients without any treatment, and 12,948 patients receiving IFN treatment. This study revealed that DAA treatment was associated with a reduced risk of HCC compared to IFN treatment after performing inverse probability of treatment weighting (adjusted HR: 0.69, 95\%CI: 0.59-0.81).

In 2019, the debate on the interplay between DAA and HCC continued, and Carrat et al. ${ }^{[24]}$ and Ide et al. ${ }^{[25]}$ published prospective cohort studies. In the former study in France, 7344 patients with DAA treatment, and 2551 patients without treatment were enrolled ${ }^{[24]}$. DAA treatment seems to increase the risk of HCC (HR: 2.77, 95\%CI: 2.07-3.71). However, after adjustment for variables, DAA treatment was associated with a decrease in HCC (adjusted HR: 0.66, 95\%CI: 0.46-0.91) and all-cause mortality (adjusted HR: 0.48, 95\%CI: $0.33-0.70)$. A prospective study from Japan by Ide et al. ${ }^{[25]}$ enrolled 2552 patients who were treated with DAAs and achieved a SVR. The three-year cumulative incidence of HCC was $4.9 \%$ in all patients, $10.0 \%$ in patients with cirrhosis, and $2.9 \%$ in patients without cirrhosis. They concluded that DAAs do not increase the risk of HCC occurrence after achieving SVR.

\section{THE INTERPLAY BETWEEN DIRECT-ACTING ANTIVIRALS AND RECURRENCE OF HEPATOCELLULAR CARCINOMA}

HCC is treated with curative treatment or non-curative interventions according to tumor stage, liver function, and performance status. After curative treatment such as surgical resection for HCC, the risk of recurrence is $60 \%-70 \%$ at five years ${ }^{[26,27]}$. Several studies have shown that adjuvant IFN therapy after curative treatment can reduce the recurrence rate of $\mathrm{HCC}^{[28-32]}$.

The papers published on the HCC recurrence after DAA treatment are organized in Table 2. Despite expectations that achieving SVR after DAA treatment will reduce the recurrence of HCC, Reig et al. ${ }^{[13]}$ reported an unexpected high rate of early tumor recurrence in patients with HCV-related HCC undergoing DAA therapy in 2016. The study included 58 patients with prior history of treated HCC with complete response who lacked "non-characterized nodules". They reported unexpected high recurrence rate of $27.6 \%$ and median time from DAA start to recurrence was 3.5 months (range 1.1-8 months). Conti et al. ${ }^{[14]}$ published another similar report about early recurrence of HCC. In this retrospective cohort study, the recurrence rate of HCC after completing DAA therapy was $28.81 \%$ (17 of 59 patients, $95 \%$ CI: 17.76-42.07) during the 24-week post-treatment evaluation. Fifty-nine patients with a history of previous HCC included 11 patients who received transarterial chemoembolization". This term has only been mentioned once for previous HCC. The study indicated that patients previously treated for HCC still have a high risk of tumor recurrence.

Opposite opinions to the previous paper were subsequently published. One prospective study used three French multicenter ANRS cohorts ${ }^{[33]}$. The DAA group and untreated group were analyzed and the rate 


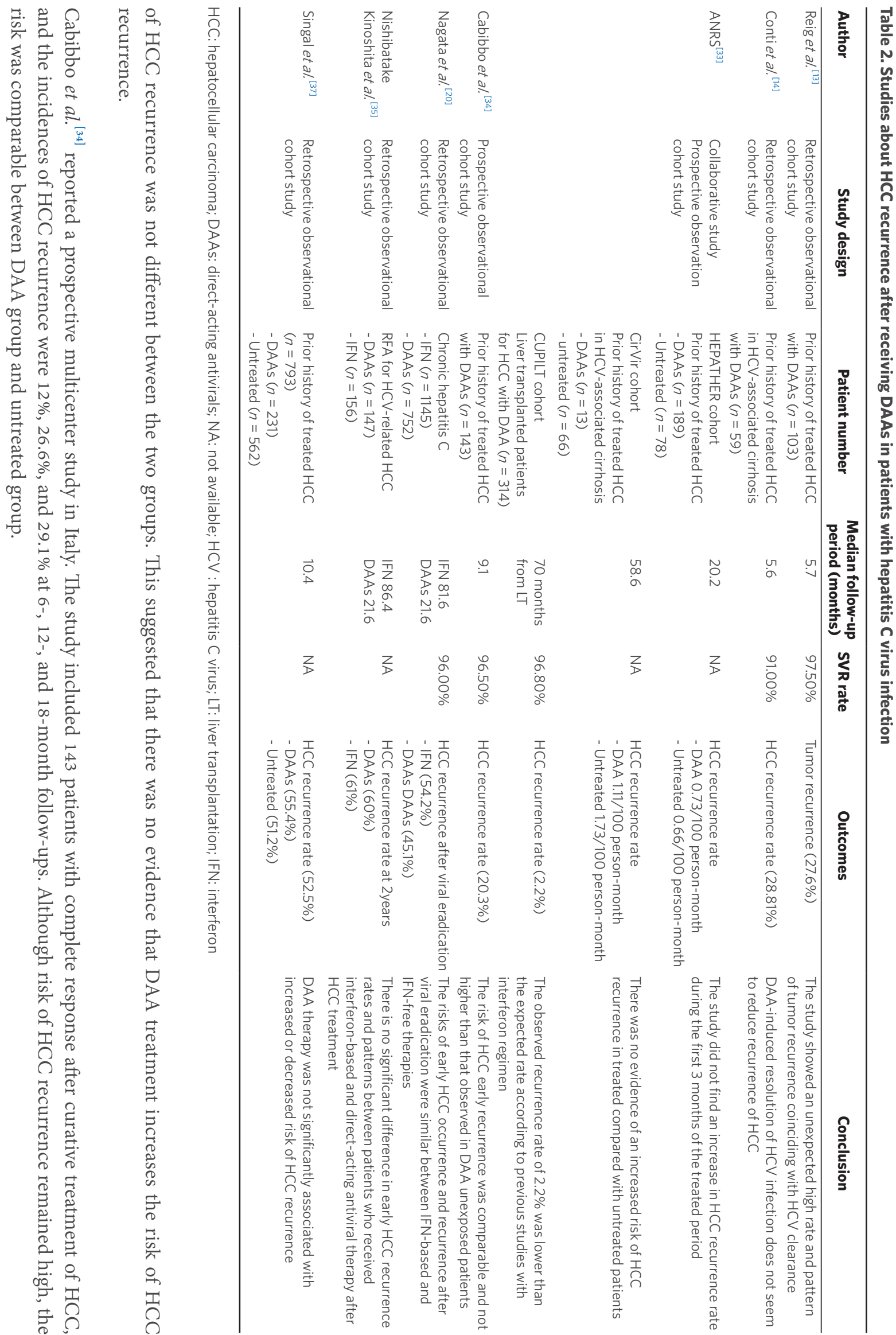


Table 3. Risk factors for occurrence/recurrence of HCC

\begin{tabular}{|c|c|c|}
\hline Author/Study design & Occurrence/Recurrence & Risk factors for the development of HCC \\
\hline \multirow[t]{2}{*}{ Conti et al. ${ }^{[14]}$} & Occurrence & No associate factor \\
\hline & Recurrence & Age, liver stiffness \\
\hline Kanwal et al. ${ }^{[17]}$ & Occurrence & non-SVR, alcohol use, non-African Americans, cirrhosis \\
\hline Calvaruso et al. ${ }^{[18]}$ & Occurrence & Albumin $<3.5 \mathrm{~g} / \mathrm{dL}$, platelet count $<120 \times 10^{9} / \mathrm{L}$, absence of SVR \\
\hline Romano et al. ${ }^{[19]}$ & Occurrence & Positive for $\mathrm{HBsAg}$, APRI score $\geq 2.5, \mathrm{CPC} B$, treatment failure \\
\hline \multirow[t]{2}{*}{ Nagata et al. ${ }^{[20]}$} & Occurrence & IL-28 genetic polymorphism, post-treatment WFA*M2BP \\
\hline & Recurrence & IL-28 genetic polymorphism, post-treatment WFA*M2BP \\
\hline Nahon et al. ${ }^{[21]}$ & Occurrence & $\begin{array}{l}\text { non-SVR, older age, excessive alcohol consumption, lower platelet count, high } \\
\text { GGT levels, HCV genotype } 1\end{array}$ \\
\hline loannou et al. ${ }^{[42]}$ & Occurrence & non-SVR, cirrhosis \\
\hline Yoo et al. ${ }^{[22]}$ & Occurrence & Alpha-fetoprotein level $>9.5 \mathrm{ng} / \mathrm{mL}$ \\
\hline Singer et $a l^{[23]}$ & Occurrence & $\begin{array}{l}\text { Older age, male gender, cirrhosis, thrombocytopenia, portal hypertension, } \\
\text { diabetes, tobacco use, alcoholic liver disease }\end{array}$ \\
\hline Carrat et al. ${ }^{[24]}$ & Occurrence & Untreated, non-SVR \\
\hline Ide et $\left.a\right|_{.[25]} ^{[25}$ & Occurrence & Age $\geq 62$ years old, male gender, FIB- 4 index $\geq 4.6$, and GGTP level $\geq 44 \mathrm{IU} / \mathrm{L}$ \\
\hline Cabibbo et $a l^{[34]}$ & Recurrence & Main tumor size $>2.5 \mathrm{~cm}$, history of prior recurrence \\
\hline Nishibatake Kinoshita et al. ${ }^{[35]}$ & Recurrence & $\begin{array}{l}\text { Higher lens culinaris agglutinin-reactive fraction of alpha-fetoprotein level, } \\
\text { a history of multiple HCC treatments, and a shorter interval between HCC } \\
\text { treatment and initiation of antiviral therapy }\end{array}$ \\
\hline Singal et $a .^{[37]}$ & Recurrence & No associate factor \\
\hline
\end{tabular}

HCC: hepatocellular carcinoma; SVR: sustained virological response; CPC: Child-Pugh Class; HCV: hepatitis C virus; IFN: interferon

The retrospective cohort study from Japan by Nagata et al. ${ }^{[20]}$ analyzed 60 patients in the IFN-based therapy group and 83 patients in the IFN-free therapy group. The incidence of HCC recurrence after locally curative treatment was not significantly different between IFN-based and IFN-free therapy groups by propensity score-matched analysis (five-year incidence: $54.2 \%$ in IFN-based and $45.1 \%$ in IFN-free therapy, $P=0.54$ ). Nishibatake Kinoshita et al. ${ }^{[35]}$ enrolled HCC patients previously treated with radiofrequency ablation (147 patients in DAA group and 156 patients in IFN group). The rate of HCC recurrence at one and two years was $39 \%$ and $61 \%$ in IFN group and $39 \%$ and $60 \%$ in DAA group, respectively $(P=0.43)$. There was also no significant difference between the two groups after performing matching analysis $(P=0.68)$. To compare the rate of HCC recurrence between the patients who received DAA and IFN-based therapies, Waziry et al. ${ }^{[36]}$ published meta-analyses study containing 17 studies. The incidence of HCC recurrence after SVR was 9.21 per 100 person-year in DAA group and 12.16 per 100 person-year in IFN group. After adjusting analysis, DAA treatment was not associated with HCC recurrence (Relative risk: 0.62, 95\%CI: 0.11-3.45, $P=0.56$ ). To solve this debate firmly, a large study from USA and Canada was published by Singal et al. ${ }^{[37]}$ in 2019. In total, 793 patients with HCV-associated HCC, including 304 patients who received DAA and 489 patients without treatment, were analyzed. HCC recurred in $42.1 \%$ patients in the DAA group and $58.9 \%$ in the untreated group. Although DAA treatment seems to decrease the risk of HCC recurrence (HR: 0.32, 95\%CI: 025-0.41), after accounting for time-varying exposure, DAA treatment was not associated with increasing or decreasing the risk of HCC recurrence after complete response (HR: 0.90, 95\%CI: 0.70-1.16).

\section{RISK FACTORS FOR OCCURRENCE/RECURRENCE OF HEPATOCELLULAR CARCINOMA AFTER TREATING WITH DIRECT-ACTING ANTIVIRALS}

In most of the studies on the interplay between DAA and HCC, non-SVR, advanced liver disease, and older age were associated with risk of HCC. Table 3 contains the risk factors for development of HCC.

In a report about the early occurrence and recurrence of HCC in HCV-related cirrhosis treated with DAA, Child-Pugh class (OR: 4.18, 95\%CI: 1.17-14.8, $P=0.03$ ) and history of HCC (OR: 12.0, 95\%CI: 4.02-35.74, $P<0.0001)$ were associated with HCC development. There was no significant factor in patients without history of previous HCC, while age (OR: 0.82, 95\%CI: 0.69-0.97, $P=0.02)$ and liver stiffness (OR: 1.19, 
95\%CI: 1.01-1.39, $P=0.03$ ) were significant factors prone to experience HCC recurrence ${ }^{[14]}$. A study from Japan reported on the impact of DAA on early recurrence of HCC and higher alpha-fetoprotein (AFP)-L3 level (HR: 1.47, 95\%CI: 1.02-2.11, $P=0.04$ ), larger number of HCC treatments (HR: 1.65, 95\%CI: 1.16-2.35, $P=0.007$ ), and shorter interval between the last HCC treatment and initiation of antiviral therapy $(P=0.007)$ were associated with the risk of HCC recurrence ${ }^{[35]}$. In the comparative study for occurrence and recurrence of HCC in IFNbased and IFN-free therapies, AFP and WFA ${ }^{\star} \mathrm{M} 2 \mathrm{BP}$ levels were significantly associated with HCC occurrence after achieving an $\mathrm{SVR}^{[20]}$. This study suggested that $\mathrm{AFP}>5.4 \mathrm{ng} / \mathrm{mL}$ and $\mathrm{WFA}^{\star} \mathrm{M} 2 \mathrm{BP}>1.8 \mathrm{COI}$ could be helpful markers of HCC occurrence. A prospective cohort study including 2249 patients with HCV-associated cirrhosis reported that albumin level $<3.5 \mathrm{~g} / \mathrm{dL}$ (HR: 1.77, 95\%CI: 1.12-2.82, $P=0.01$ ), platelet count $<120 \times$ $10^{9} /$ L (HR: 3.89, 95\%CI: 2.11-7.15, $P<0.001$ ), and absence of SVR (HR: 3.40, 95\%CI: $1.89-6.12, P<0.001$ ) were associated with an increased risk of HCC occurrence ${ }^{[18]}$.

The retrospective cohort study using national data of 22,500 patients revealed that the patients with SVR (HR: 0.24, 95\%CI: 0.19-0.31, $P<0.0001$ ) and African American patients (HR: 0.56, 95\%CI: 0.39-0.81, $P=0.02$ ) were associated with low risk of HCC $^{[17]}$. Patients with cirrhosis (HR: 4.73, 95\%CI: 3.34-6.68, $P<0.0001$ ) and alcohol abuse (HR: $1.56,95 \% \mathrm{CI}: 1.11-2.18, P=0.01$ ) were associated with high incidence of HCC. A large, prospective, population-based study from Italy including 3917 patients with fibrosis stage $\geq$ F3 revealed that DAA treatment failure (HR: 9.09, 95\%CI: 5.2-16.1, $P=0.0001$ ), HBV coinfection (HR: 3.99, 95\%CI: 1.24-12.91, $P=0.021$ ), and APRI score $>2.5$ (HR: 2.03, 95\%CI: 1.14-3.61, $P=0.016$ ) were significantly associated with HCC occurrence ${ }^{[19]}$. A comparative study including DAA group, SVR-IFN group, and non-SVR group suggested that increased age, alcohol consumption, HCV genotype 1, and impaired liver function were statistically significantly associated with risk of $\mathrm{HCC}^{[21]}$. There was no significant association between DAA use and risk of HCC. In our study, we compared the rates of HCC between DAA group and IFN group, and alpha-fetoprotein $>9.5 \mathrm{ng} / \mathrm{mL}$ at the time of end-of treatment response was the only significant risk factor for HCC occurrence ${ }^{[22]}$. Moreover, in a prospective study in France, exposure to DAA was strongly associated with a decrease in all-cause mortality (adjusted HR: 0.34, 95\%CI: $0.22-0.55, P<0.0001$ ) and risk of HCC (adjusted HR: 0.57, 95\%CI: 0.40-0.81 $P=0.016{ }^{[24]}$. A study including HCV patients with received DAAs and who achieved SVR showed that male gender (HR: 2.40, 95\%CI: 1.46-3.96, $P=0.0006$ ), older age (HR: $1.51,95 \%$ CI: 1.20-1.91, $P=0.0005$ ), higher FIB-4 index (HR: 1.12, 95\%CI: $1.07-1.17, P<0.0001$ ), and higher GGTP level (HR: 1.04, 95\%CI: 1.02-1.06, $P<0.0001)$ were independently associated with HCC occurrence ${ }^{[25]}$.

\section{CONCLUSION}

Since the initial reports about the unexpected high rate of early recurrence of HCC were published, most recent reports showed favorable effects of DAA treatment in regard to HCC occurrence/recurrence. Several published studies have indicated that non-SVR, older age, advanced liver disease, combined liver disease (chronic hepatitis B and alcohol abuse), higher AFP, and history of previous HCC may play roles in increasing HCC risk. Accordingly, the Asian Pacific Association for the Study of the Liver guidelines suggest that surveillance be performed every six months for patients with SVR and liver cirrhosis and every four months for patients with SVR and previous history of $\mathrm{HCC}^{[38]}$. Achieving SVR in patients with HCV improved their outcomes in terms of deaths, Child-Pugh Class, and model for end-stage liver disease of advanced liver disease, as well as the incidence of HCC. In addition, patients with previous HCC after achieving SVR had significantly better survival than untreated patients, thus patients eligible for HCC therapy should be considered for DAA treatment ${ }^{[39]}$. However, the risk of HCC is not completely eliminated by achieving SVR after DAA treatment, and regular surveillance of HCC including biomarkers for tumor should be considered in patients with cirrhosis, combined liver disease, and previous history of HCC ${ }^{[40,41]}$. 


\section{DECLARATIONS}

\section{Authors' contributions}

Study concept and design: Yoo SH, Kwon JH

Acquisition of data: Yoo SH

Drafting of the manuscript: Yoo SH

Study supervision: Kwon JH

\section{Availability of data and materials}

Not applicable.

\section{Financial support and sponsorship}

None.

\section{Conflicts of interest}

All authors declared that there are no conflicts of interest.

\section{Ethical approval and consent to participate}

Not applicable.

\section{Consent for publication}

Not applicable.

\section{Copyright}

(c) The Author(s) 2020.

\section{REFERENCES}

1. Marrero JA, Kulik LM, Sirlin CB, Zhu AX, Finn RS, et al. Diagnosis, staging, and management of hepatocellular carcinoma: 2018 practice guidance by the American association for the study of liver diseases. Hepatology 2018;68:723-50.

2. Manns MP, McHutchison JG, Gordon SC, Rustgi VK, Shiffman M, et al. Peginterferon alfa-2b plus ribavirin compared with interferon alfa-2b plus ribavirin for initial treatment of chronic hepatitis C: a randomised trial. Lancet 2001;358:958-65.

3. Zeuzem S, Hultcrantz R, Bourliere M, Goeser T, Marcellin P, et al. Peginterferon alfa-2b plus ribavirin for treatment of chronic hepatitis C in previously untreated patients infected with HCV genotypes 2 or 3. J Hepatol 2004;40:993-9.

4. Lee SD, Yu ML, Cheng PN, Lai MY, Chao YC, et al. Comparison of a 6-month course peginterferon alpha-2b plus ribavirin and interferon alpha-2b plus ribavirin in treating Chinese patients with chronic hepatitis C in Taiwan. J Viral Hepat 2005;12:283-91.

5. Morgan TR, Ghany MG, Kim HY, Snow KK, Shiffman ML, et al; Group H-CT. Outcome of sustained virological responders with histologically advanced chronic hepatitis C. Hepatology 2010;52:833-44.

6. Lok AS, Everhart JE, Wright EC, Di Bisceglie AM, Kim HY, et al; Group H-CT. Maintenance peginterferon therapy and other factors associated with hepatocellular carcinoma in patients with advanced hepatitis C. Gastroenterology 2011;140:840-9.

7. van der Meer AJ, Veldt BJ, Feld JJ, Wedemeyer H, Dufour JF, et al. Association between sustained virological response and all-cause mortality among patients with chronic hepatitis $C$ and advanced hepatic fibrosis. JAMA 2012;308:2584-93.

8. Kowdley KV, Lawitz E, Poordad F, Cohen DE, Nelson DR, et al. Phase $2 b$ trial of interferon-free therapy for hepatitis C virus genotype 1. N Engl J Med 2014;370:222-32.

9. Lawitz E, Poordad FF, Pang PS, Hyland RH, Ding X, et al. Sofosbuvir and ledipasvir fixed-dose combination with and without ribavirin in treatment-naive and previously treated patients with genotype 1 hepatitis $\mathrm{C}$ virus infection (LONESTAR): an open-label, randomised, phase 2 trial. Lancet 2014;383:515-23.

10. Muir AJ, Poordad F, Lalezari J, Everson G, Dore GJ, et al. Daclatasvir in combination with asunaprevir and beclabuvir for hepatitis C virus genotype 1 infection with compensated cirrhosis. JAMA 2015;313:1736-44.

11. Lawitz E, Makara M, Akarca US, Thuluvath PJ, Preotescu LL, et al. Efficacy and safety of ombitasvir, paritaprevir, and ritonavir in an open-label study of patients with genotype $1 \mathrm{~b}$ chronic hepatitis $\mathrm{C}$ virus infection with and without cirrhosis. Gastroenterology 2015;149:971-80.e1.

12. Kwon JH, Yoo SH, Nam SW, Kim HY, Kim CW, et al. Clinical outcomes after the introduction of direct antiviral agents for patients infected with genotype $1 \mathrm{~b}$ hepatitis C virus depending on the regimens: A multicenter study in Korea. J Med Virol 2019;91:1104-11.

13. Reig M, Marino Z, Perello C, Inarrairaegui M, Ribeiro A, et al. Unexpected high rate of early tumor recurrence in patients with HCVrelated HCC undergoing interferon-free therapy. J Hepatol 2016;65:719-26.

14. Conti F, Buonfiglioli F, Scuteri A, Crespi C, Bolondi L, et al. Early occurrence and recurrence of hepatocellular carcinoma in HCV- 
related cirrhosis treated with direct-acting antivirals. J Hepatol 2016;65:727-33.

15. Masuzaki R, Tateishi R, Yoshida H, Yoshida H, Sato S, et al. Risk assessment of hepatocellular carcinoma in chronic hepatitis C patients by transient elastography. J Clin Gastroenterol 2008;42:839-43.

16. Goodgame B, Shaheen NJ, Galanko J, El-Serag HB. The risk of end stage liver disease and hepatocellular carcinoma among persons infected with hepatitis C virus: publication bias? Am J Gastroenterol 2003;98:2535-42.

17. Kanwal F, Kramer J, Asch SM, Chayanupatkul M, Cao Y, et al. Risk of hepatocellular cancer in HCV patients treated with directacting antiviral agents. Gastroenterology 2017;153:996-1005.e1.

18. Calvaruso V, Cabibbo G, Cacciola I, Petta S, Madonia S, et al; Rete Sicilia Selezione Terapia HCV. Incidence of hepatocellular carcinoma in patients with HCV-associated cirrhosis treated with direct-acting antiviral agents. Gastroenterology 2018;155:411-21.e4.

19. Romano A, Angeli P, Piovesan S, Noventa F, Anastassopoulos G, et al. Newly diagnosed hepatocellular carcinoma in patients with advanced hepatitis C treated with DAAs: A prospective population study. J Hepatol 2018;69:345-52.

20. Nagata H, Nakagawa M, Asahina Y, Sato A, Asano Y, et al; Ochanomizu Liver Conference Study G. Effect of interferon-based and -free therapy on early occurrence and recurrence of hepatocellular carcinoma in chronic hepatitis C. J Hepatol 2017;67:933-9.

21. Nahon P, Layese R, Bourcier V, Cagnot C, Marcellin P, et al; Group ACC. Incidence of Hepatocellular Carcinoma After Direct Antiviral Therapy for HCV in Patients With Cirrhosis Included in Surveillance Programs. Gastroenterology 2018;155:1436-50.e6.

22. Yoo SH, Kwon JH, Nam SW, Kim HY, Kim CW, et al. Early development of de novo hepatocellular carcinoma after direct-acting agent therapy: comparison with pegylated interferon-based therapy in chronic hepatitis C patients. J Viral Hepat 2018;25:1189-96.

23. Singer AW, Reddy KR, Telep LE, Osinusi AO, Brainard DM, et al. Direct-acting antiviral treatment for hepatitis C virus infection and risk of incident liver cancer: a retrospective cohort study. Aliment Pharmacol Ther 2018;47:1278-87.

24. Carrat F, Fontaine H, Dorival C, Simony M, Diallo A, et al; French ACOHc. Clinical outcomes in patients with chronic hepatitis C after direct-acting antiviral treatment: a prospective cohort study. Lancet 2019;393:1453-64.

25. Ide T, Koga H, Nakano M, Hashimoto S, Yatsuhashi H, et al. Direct-acting antiviral agents do not increase the incidence of hepatocellular carcinoma development: a prospective, multicenter study. Hepatol Int 2019;13:293-301.

26. Poon RT, Fan ST, Lo CM, Liu CL, Wong J. Long-term survival and pattern of recurrence after resection of small hepatocellular carcinoma in patients with preserved liver function: implications for a strategy of salvage transplantation. Ann Surg 2002;235:373-82.

27. Tabrizian P, Jibara G, Shrager B, Schwartz M, Roayaie S. Recurrence of hepatocellular cancer after resection: patterns, treatments, and prognosis. Ann Surg 2015;261:947-55.

28. Shen YC, Hsu C, Chen LT, Cheng CC, Hu FC, et al. Adjuvant interferon therapy after curative therapy for hepatocellular carcinoma (HCC): a meta-regression approach. J Hepatol 2010;52:889-94.

29. Ikeda K, Arase Y, Saitoh S, Kobayashi M, Suzuki Y, et al. Interferon beta prevents recurrence of hepatocellular carcinoma after complete resection or ablation of the primary tumor-A prospective randomized study of hepatitis $\mathrm{C}$ virus-related liver cancer. Hepatology 2000;32:228-32.

30. Kubo S, Nishiguchi S, Hirohashi K, Tanaka H, Shuto T, et al. Effects of long-term postoperative interferon-alpha therapy on intrahepatic recurrence after resection of hepatitis $\mathrm{C}$ virus-related hepatocellular carcinoma. A randomized, controlled trial. Ann Intern Med 2001;134:963-7.

31. Lin SM, Lin CJ, Hsu CW, Tai DI, Sheen IS, et al. Prospective randomized controlled study of interferon-alpha in preventing hepatocellular carcinoma recurrence after medical ablation therapy for primary tumors. Cancer 2004;100:376-82.

32. Mazzaferro V, Romito R, Schiavo M, Mariani L, Camerini T, et al; Force HCCIT. Prevention of hepatocellular carcinoma recurrence with alpha-interferon after liver resection in HCV cirrhosis. Hepatology 2006;44:1543-54.

33. ANRS collaborative study group on hepatocellular carcinoma. Lack of evidence of an effect of direct-acting antivirals on the recurrence of hepatocellular carcinoma: data from three ANRS cohorts. J Hepatol 2016;65:734-40.

34. Cabibbo G, Petta S, Calvaruso V, Cacciola I, Cannavo MR, et al; Rete Sicilia Selezione Terapia HCV. Is early recurrence of hepatocellular carcinoma in HCV cirrhotic patients affected by treatment with direct-acting antivirals? A prospective multicentre study. Aliment Pharmacol Ther 2017;46:688-95.

35. Nishibatake Kinoshita M, Minami T, Tateishi R, Wake T, Nakagomi R, et al. Impact of direct-acting antivirals on early recurrence of HCV-related HCC: comparison with interferon-based therapy. J Hepatol 2019;70:78-86.

36. Waziry R, Hajarizadeh B, Grebely J, Amin J, Law M, et al. Hepatocellular carcinoma risk following direct-acting antiviral HCV therapy: A systematic review, meta-analyses, and meta-regression. J Hepatol 2017;67:1204-12.

37. Singal AG, Rich NE, Mehta N, Branch A, Pillai A, et al. Direct-Acting Antiviral Therapy Not Associated With Recurrence of Hepatocellular Carcinoma in a Multicenter North American Cohort Study. Gastroenterology 2019;156:1683-92.e1.

38. Kanda T, Lau GKK, Wei L, Moriyama M, Yu ML, et al. APASL HCV guidelines of virus-eradicated patients by DAA on how to monitor HCC occurrence and HBV reactivation. Hepatol Int 2019;13:649-61.

39. Dang H, Yeo YH, Yasuda S, Huang CF, Iio E, et al. Cure with Interferon Free DAA is Associated with Increased Survival in Patients with HCV related HCC from both East and West. Hepatology 201910.1002/hep.30988.

40. Cheung MCM, Walker AJ, Hudson BE, Verma S, McLauchlan J, et al; UK HCVR. Outcomes after successful direct-acting antiviral therapy for patients with chronic hepatitis C and decompensated cirrhosis. J Hepatol 2016;65:741-7.

41. Hanafy AS, Bassiony MA, Basha MAA. Management of HCV-related decompensated cirrhosis with direct-acting antiviral agents: who should be treated? Hepatol Int 2019;13:165-72.

42. Ioannou GN, Green PK, Berry K. HCV eradication induced by direct-acting antiviral agents reduces the risk of hepatocellular carcinoma. J Hepatol 2018;1:25-32. 